\title{
Caracterização do sistema vocálico do português culto falado em Angola
}

\author{
Márcio UNDOLO \\ CIDEHUS - Universidade de Évora, Portugal \\ marindolo@hotmail.com
}

\begin{abstract}
RESUMO
O presente artigo situa-se nos domínios de especialidade da Fonética e Fonologia. Pretende-se, com efeito, destacar algumas características fonético-fonológicas do português culto falado em Angola, nomeadamente no domínio do vocalismo, identificadas e recolhidas de enunciados orais de cidadãos angolanos e residentes em Angola, estudantes e profissionais com nível de instrução médio-alto. No falar português desses indivíduos constam elementos que se opõem a determinados usos e hábitos linguísticos normativos do Português europeu, recomendados como usos e hábitos oficiais. Procura-se, assim, demonstrar que, pelo menos em relação ao sistema vocálico, o português angolano das camadas cultas da população difere do Português europeu.
\end{abstract}

Palavras-chave: sistema vocálico, português culto, português de Angola, norma.

[Recibido, mayo 2013; aprobado, septiembre 2013]

Characteristics of the vowel system of the

Standard Portuguese spoken in Angola

\begin{abstract}
This article relates to specific areas of Phonetics and Phonology. It is intended, in effect, to highlight some characteristics of the educated spoken Portuguese in Angola, identified and collected from oral speeches of Angolan citizens and residents in Angola, students and professionals with medium-high level of scholarship. The speech of these individuals contains certain elements that differ from the linguistic norm at use in European Portuguese, recommended as the usage in Angola. At least with respect to the vowel system, it is shown that the vowel system of these individuals differs from the European Portuguese.
\end{abstract}

Key-words: vowels system, Standard Portuguese, Angolan Portuguese, standard. 


\section{Introdução}

Em Angola, a língua portuguesa tem vindo a sofrer transformações nos seus mais variados níveis, nomeadamente fonético, fonológico, morfológico, sintáctico e lexical.

Particularmente nos enunciados orais construídos com base na norma europeia, o Português europeu (PE), estabelecida como referência em contexto formal de comunicação, são notáveis os efeitos de tais transformações linguísticas e gramaticais, estabelecendo-se diferenças sensíveis entre o português oficial (PE) e o português real (de acordo com hábitos linguísticos próprios da sociedade angolana).

Neste artigo, o nosso foco incide sobre o que se pode chamar português real culto, por comparação com o português oficial em Angola. No âmbito da pretendida análise, constitui objecto de estudo o sistema vocálico desse português real culto ${ }^{1}$, objectivando a sua descrição e compreensão, com base num corpus oral espontâneo, recolhido recentemente junto da classe mais instruída da sociedade angolana (entre estudantes universitários, professores, jornalistas e distintos agentes da função pública e do sector privado).

Tomamos, assim, como ponto de partida, a constatação de que aquilo a que se pode dar o nome de sistema vocálico do português culto em Angola é caracterizado, no seu aspecto físico e funcional, por elementos que o diferenciam do sistema vocálico do $\mathrm{PE}$, identificando e exemplificando estas diferenças e, finalmente, propondo um quadro actualizado do sistema vocálico do português culto angolano actual acompanhado de uma análise explicativa.

Estruturalmente, este trabalho apresenta dois pontos principais. $\mathrm{O}$ primeiro ponto aborda essencialmente dois aspectos, a saber: (i) os fonemas que constituem o sistema vocálico do PE e seus valores fónicos e, posto isto, (ii) as diferenças que se estabelecem entre este sistema e aquele que representa o sistema vocálico do português real culto em Angola, designado, a partir daqui, por Português de Angola: PA. O segundo ponto consiste numa abordagem teórica em que tentamos explicar e justificar o sistema vocálico do PA.

\section{Análise contrastiva entre características fonéticas do PE e do PA}

\subsection{Vogais do $P E$}

O sistema vocálico do PE é constituído por catorze vogais, nove orais e cinco nasais, a que acrescem quatro semivogais, duas orais e duas nasais.

$\mathrm{O}$ quadro que apresentamos abaixo lembra as classificações do vocalismo do PE, segundo os seguintes parâmetros referentes ao tracto vocal supralaríngeo:

- estado do véu palatino - oral e nasal;

- zona longitudinal de articulação - palatal, central e velar;

- abertura vocálica - aberta, média e fechada.

\footnotetext{
1 Adoptamos esta designação no sentido que lhe atribui Miguel (2003:37): «a língua das classes mais instruídas da sociedade».
} 


\begin{tabular}{|c|l|c|l|}
\hline \multicolumn{2}{|c|}{ Vogais orais } & \multicolumn{2}{c|}{ Vogais nasais } \\
\hline classificação & \multicolumn{1}{|c|}{ exemplo } & classificação & exemplo \\
\hline central aberta & {$[\mathrm{a}]-$ mala } & central média & {$[\tilde{\mathrm{e}}]-$ canto } \\
\hline central média & {$[\mathrm{e}]-$ mala } & palatal média & {$[\tilde{\mathrm{e}}]-$ pente } \\
\hline central fechada & {$[\mathrm{i}]-$ me } & palatal fechada & {$[\tilde{1}]-$ pinto } \\
\hline palatal aberta & {$[\varepsilon]-$ pé } & velar média & {$[\tilde{o}]-$ conto } \\
\hline palatal média & {$[\mathrm{e}]-$ medo } & velar fechada & {$[\tilde{u}]-$ fundo } \\
\hline palatal fechada & {$[\mathrm{i}]-$ ninho } & & \\
\hline velar aberta & {$[\mathrm{o}]-$ pó } & & \\
\hline velar média & {$[\mathrm{o}]-$ força } & & \\
\hline velar fechada & {$[\mathrm{u}]-$ cume } & & \\
\hline
\end{tabular}

\subsection{Vogais do $P A$}

No falar português de indivíduos nacionais residentes em Angola, que integram a franja escolarizada da sociedade, com níveis de ensino médio ou superior, com diferentes ocupações profissionais, identificámos alguns aspectos relativos ao vocalismo que diferem de determinados usos e hábitos linguísticos normativos do PE, recomendados como usos e hábitos oficiais, nomeadamente na Televisão, Rádio, escola, etc.

Nomeadamente, verificam-se diferenças entre os sistemas vocálicos do PA e do PE nos seguintes casos:

(1) $[\mathbf{e}]$

Ao contrário do que se verifica no $\mathrm{PE}$, não observamos a realização da vogal oral central média em posição átona final ${ }^{2}$, mantendo-se a vogal aberta: ['kaza].

(2) $[\varepsilon]$

No PA, esta vogal, em posição tónica, tende a ser mais frequente do que a vogal oral palatal média [e], na mesma posição. Não são raros os casos em que, inclusive, ela substitui a vogal oral palatal média [e], sempre na mesma posição. Por exemplo: [bi'leze], no PE, face a [be'leza], no PA.

(3) [i] final:

Ao contrário do $\mathrm{PE}$, a realização desta vogal no PA restringe-se à posição átona

- ['disi] no PE; e, igualmente, ['disi] no PA;

- [prizi'dẽti] no PE e [prezi'dẽti] no PA.

Em posição pretónica, ao contrário do que acontece em $\mathrm{PE}$, esta vogal não se centraliza, mantendo-se a palatal média [e]:

- [etrupi'łar] no PE, e [atrope'łar] no PA;

- [ẽpubri'ser] no PE e [ẽpobre'ser] no PA.

\footnotetext{
${ }^{2}$ Lembre-se que a inexistência desta vogal já tinha sido confirmada no PA popular (cf. Carrasco, 1988).
} 
(5) [0]

No PA, esta vogal é mais frequente do que a vogal velar média [o], em posição tónica, o que corrobora a tendência, verificada também nas vogais centrais e palatais, para a abertura das vogais nesta posição. Tome-se como exemplo os seguintes casos:

- [diz'goftu] no PE e [dez'goftu] no PA;

- [e'vo], nome masculino, no PE; e [a'vo] para indicar o mesmo género, no PA.

(6) [o]

Esta vogal, em alguns casos, ocorre em substituição da vogal velar fechada $[u]^{3}$, em posição pretónica.

- [mu'rar] no PE e [mo'rar] no PA;

- [nemu'rar] no PE e [namo'rar] no PA.

(7) $[\tilde{\mathrm{e}}]$

$\mathrm{Na}$ nossa recolha, não registamos esta vogal. Verificamos que o que existe é uma vogal central aberta, também nasal [ã], que, por sua vez, não existe em PE, constituindo-se, assim, como um elemento exclusivo do sistema vocálico do PA:

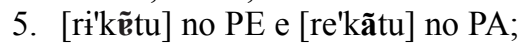

4. ['ésje] no PE e ['ãsja] no PA.

Assim, o sistema vocálico do PA possui treze vogais (ou fonemas vocálicos), menos uma do que o sistema vocálico do $\mathrm{PE}$, registando-se várias outras diferenças em função da posição: tónica, átona, pretónica ou postónica e átona final.

Tal como no PE, constata-se que é nas posições átonas que o número de fonemas vocálicos é, geralmente, reduzido, devido a fenómenos fonético-fonológicos gerais relacionados com o enfraquecimento das vogais em posição átona.

Das treze vogais do PA, oito são orais e cinco nasais, sendo que, destas últimas, uma - a vogal central aberta - é uma exclusividade do PA. Enquanto no PE temos a

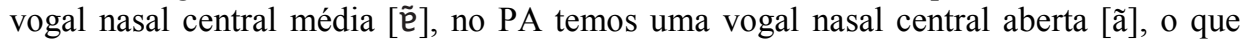
significa que, embora o PA tenha o mesmo número de vogais nasais que o $\mathrm{PE}$, elas não são totalmente coincidentes.

Em relação às vogais orais, o sistema do PA é, como vimos, mais reduzido, com apenas 13 vogais, face às 14 do $\mathrm{PE}$. Além de mais reduzido, o sistema apresenta ainda outras descoincidências.

Quanto à vogal oral central fechada [i] e às vogais orais palatais aberta $[\varepsilon]$ e média [e], a palatal média é predominante no PA quando, por oposição ao PE, substitui a central fechada em posição pretónica, e a vogal palatal aberta $[\varepsilon]$ tende a substituir a palatal média em posição tónica

Quanto às vogais velares, registamos que a velar fechada $[\mathrm{u}]$ é, geralmente, substituída pela velar média [o] em posição pretónica e, em posição tónica, a vogal aberta [0] é predominante onde no PE se encontra a média [o].

Resumindo, é possível afirmar, a partir dos dados analisados, que o sistema vocálico do PA:

\footnotetext{
${ }^{3}$ Caso curioso e, até ao momento, único é o da substituição de [o] por [u] em posição tónica, em algumas formas com [u] final: ['komu] no PE e ['kumu] no PA. Neste caso, a realização com [u] caracteriza a conjunção/advérbio, por oposição à forma verbal, com [o].
} 
a) tem menos um elemento oral do que o do PE: [e] ;

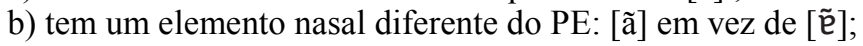

c) regista uma tendência para o abaixamento em posição tónica;

d) não sofre elevação e centralização em posição átona;

e) a realização de [i] restringe-se à posição àtona final, ao contrário do $\mathrm{PE}$, onde também ocorre em posição átona pretónica.

Posto isto, o quadro que se segue é uma representação do vocalismo do PA:

\begin{tabular}{|c|l|c|c|}
\hline \multicolumn{2}{|c|}{ Vogais orais } & \multicolumn{2}{c|}{ Vogais nasais } \\
\hline classificação & \multicolumn{1}{|c|}{ exemplo } & classificação & exemplo \\
\hline central aberta & {$[\mathrm{a}]-$ mala } & central aberta & {$[\tilde{a}]-$ canto } \\
\hline & & palatal média & {$[\tilde{\mathrm{e}}]-$ pente } \\
\hline central fechada & {$[\tilde{\mathrm{i}}]-$ me } & palatal fechada & {$[\tilde{1}]-$ pinto } \\
\hline palatal aberta & {$[\varepsilon]-$ pé } & velar média & {$[\tilde{o}]-$ conto } \\
\hline palatal média & {$[\mathrm{e}]-$ medo } & velar fechada & {$[\tilde{u}]-$ fundo } \\
\hline palatal fechada & {$[\mathrm{i}]-$ ninho } & & \\
\hline velar aberta & {$[0]-$ pó } & & \\
\hline velar média & {$[\mathrm{o}]-$ morar } & & \\
\hline velar fechada & {$[\mathrm{u}]-$ cume } & & \\
\hline
\end{tabular}

\section{Conclusões}

A constatação de que o português em Angola, no seu uso oral, se distancia cada vez mais do PE pode ser explicada e demonstrada em diferentes aspectos, sendo um dos mais sensíveis o do vocalismo, que tratámos aqui.

Neste caso, importa averiguar se mudanças como as referidas indiciam, ou não, uma evolução do português em Angola que permita a confirmação da teoria segundo a qual está em constituição uma terceira norma do Português: a do Português de Angola, que vem juntar-se às duas normas já consolidadas: a do Português Europeu e a do Português do Brasil.

O português é, desde 1975, a língua oficial da República de Angola. E, enquanto língua oficial, segue a norma europeia (cf. Teyssier, 1993). Por este motivo, o português, na sua variedade europeia, é a língua da Administração Pública, dos órgãos de comunicação social, do ensino, da literatura e dos mais distintos sectores artísticos e/ou culturais nacionais. De igual modo, não só é a língua de todo o sistema de ensino em Angola, como também constitui matéria de ensino, desde o ensino primário até ao ensino superior, em muitos casos.

Actualmente, verifica-se que o português é a língua por meio da qual os Angolanos de todas as regiões e comunidades étnicas do país estabelecem contactos e relações sociais entre si e com o exterior. Deste modo, podemos dizer que o português é a língua, não apenas de comunicação intranacional, mas também a língua de comunicação internacional.

O seu estatuto de língua oficial coabita com os de língua materna (de um número significativo de falantes, sobretudo nos centros urbanos), lingua segunda (principal) e 
língua veicular (que, anteriormente, designámos por língua intranacional, no sentido em que permite a comunicação entre grupos sociais que têm como línguas maternas diferentes línguas africanas).

Em relação ao português enquanto língua oficial, reitere-se o facto de este português, cuja base é o PE, entendido como norma, ser, «um instrumento fundamental de coesão nacional e cultural de um Estado soberano e de uma nação autónoma» (Emiliano, 2009: xiv). No entanto, este mesmo autor, e outros, como Teyssier (1993), reconhecem que o português em Angola, no seu uso oral, se distancia cada vez mais da referida norma . Pinto (2001) afirma mesmo que o português em Angola está em constante transformação, com um número crescente de empréstimos das línguas bantas ${ }^{4}$ faladas no país.

No presente trabalho, procurámos demonstrar que, pelo menos nos domínios Fonético e Fonológico, e no que se refere ao vocalismo, o PA tem algumas características próprias, que podem constituir-se como bons indicadores de que está, de facto, em construção, uma norma do PA diferente, em vários aspectos, da do PE.

Tais características são, em grande parte, devidas ao contacto que o português tem, no território angolano, com dezenas de línguas africanas autóctones e com realidades sociais, culturais e políticas muito específicas, conjunto de elementos que, segundo Mateus (2005), constituem as principais causas de mudança e de variação: causas exteriores, relacionadas com a «realidade histórica», provocam alterações internas, embora

as causas da mudança não [sejam] apenas exteriores. A mudança interna, endógena, também se dá. Os fenómenos fonéticos de supressão de consoantes e vogais, ou mesmo de palavras inteiras com menor corpo fonético [...] desenvolvem-se muitas vezes pelo mero facto de a língua ser falada, usada (Mateus 2005: 24)

Este segundo grupo de causas, apontado pela autora, ainda que não visível nos casos aqui tratados, tem seguramente o seu peso nas mudanças específicas do PA. No entanto, o multilinguismo em Angola parece ser o mais determinante a ser tido em conta para a explicação ou justificação de determinadas evoluções no PA.

Efectivamente, as características particulares identificadas no vocalismo do PA parecem corresponder a uma característica estruturante geral das línguas africanas bantu faladas em Angola: o seu sistema silábico, bastante simples e simétrico.

Por outro lado, verifica-se também que, nas línguas africanas bantu faladas em Angola, o núcleo de sílaba é, geralmente, uma vogal aberta. Daí que este facto seja um candidato potencial para justificar a tendência que os falantes angolanos têm para generalizar a abertura na realização das vogais, nomeadamente em posição tónica. Notese que parte dos falantes são bilingues, e mesmo aqueles que não o são, pela convivência e laços sociais, acabam por adoptar as características do sistema silábico das línguas bantu.

Por outro lado, tal como no PA, nos sistemas vocálicos das línguas bantu não encontramos uma vogal com o valor fónico da vogal oral central média [ $\mathrm{e}]$, constituinte do sistema vocálico do PE, o que pode, também, constituir um factor de influência destas línguas nos hábitos e usos linguísticos inerentes ao português em Angola.

\footnotetext{
${ }^{4}$ Designação que coexiste com a de «línguas bantu» e que dá conta dum grupo de línguas gramatical e lexicalmente muito parecidas: o umbundu, kimbundu, kikongu, ngagela, olunyaneka, oxihelelo, luvale, etc.
} 
Assim, se o PE constitui a norma em Angola, e, por outro lado, a «norma equivale à normalidade, isto é, ao emprego corrente observado em determinada comunidade linguística, representando, nessa perspectiva, a língua mais ouvida e mais esperada, portanto a menos marcada, a que permite tomar consciência do anormal, do não corrente e dar conta da noção de desvio» (cf. Galisson \& Coste, 1983:513), então, os exemplos que apresentámos indiciam a presença de uma outra norma do Português em Angola, diferente da do Português europeu, uma vez que constituem usos linguísticos comuns em locutores reconhecidos como capazes de ajuizar acerca do que é linguisticamente aceite e apreciável na sociedade culta angolana.

Por outro lado, importa salientar que a análise efectuada se ocupou apenas do sistema vocálico dos falantes cultos. No domínio dos falantes não cultos, as diferenças revelam-se ainda mais significativas, sendo, neste caso, o fosso que separa o PA do PE ainda mais profundo, à semelhança do que acontece também com o Português do Brasil, cujas semelhanças com o PA importará averiguar em estudos futuros.

\section{Bibliografia}

AITCHISON, Jean (1993): Introdução aos Estudos Linguísticos. Mira-Sintra: Publicações Europa-América.

AlmeIDA, Nuno Carlos de (2011): Língua Portuguesa em Timor-Leste. Lisboa: LIDEL, Edições Técnicas.

CARrasco, Agnelo (1988): Subsídios para a norma do Português falado em Angola. Tese de Licenciatura. Lubango: Instituto Superior de Ciências da Educação.

- (1991): Fonética e Fonologia do Português. D.D.I., Lubango.

CunHA, Celso \& CINTRA, Lindley (1984): Nova Gramática do Português Contemporâneo. 15. ${ }^{\mathrm{a}}$ ed. Lisboa: João Sá da Costa.

DuARTE, Inês (2000): Língua Portuguesa - instrumentos de análise. Lisboa: Universidade Aberta.

Emiliano, António (2009): Fonética do Português Europeu: descrição e transcrição. Lisboa: Guimarães Editores.

Delgado-Martins, Maria Raquel (2002): Fonética do Português: trinta anos de investigação. Lisboa: Editorial Caminho.

LUCCHESI, Dante (1998): Sistema, Mudança e Linguagem. Lisboa: Edições Colibri.

MAteus, Maria Helena Mira (2003): “Fonologia'. Gramática da Língua Portuguesa. Lisboa: Editorial Caminho.

- (2005): “A Mudança da Língua no Tempo e no Espaço”. A Língua Portuguesa em Mudança. Lisboa: Editorial Caminho.

MAURO, Tullio de (2000): Linguística Elementar. Lisboa: Editorial Estampa.

NGUngA, Armindo (2004): Introduçao à Linguística Bantu. Universidade Eduardo Mondlane, Imprensa Universitária.

PINTO, Paulo Feytor (2001): Como Pensamos a nossa Língua: E as línguas dos outros. Lisboa: Editorial Espanca.

SIMÃo, Teresa (2011): O Falar de Marvão - pronúncia, vocabulário, alcunhas, ditados e provérbios populares. Lisboa: Edições Colibri.

Teyssier, Paul (1993): História da Língua Portuguesa. Lisboa: Livraria Sá da Costa Editora.

XAIVIER, Maria Francisca \& MAteus, Maria Helena (1990): Dicionário de Termos Linguísticos. I vol. Lisboa: Edições Cosmos. 